\title{
Zu viel Impfstoff geordert - Kassen wollen Regress
}

_ Viele Krankenkassen und 2011 auch die AOK NordWest - federführend für die anderen gesetzlichen Krankenkassen in Schleswig-Holstein - fordern eine Erstattung der Kosten für überzählige saisonale Grippeimpfstoffe. Auf einige Praxen können so Regresszahlungen in vier- bis fünfstelliger Höhe zukommen. Die Anträge auf Festsetzung eines Schadens im Einzelfall werden mit der von den Praxen abgeforderten Impfstoffmenge begründet und $z$. B. der Anzahl der Influenza-Abrechnungsziffern gegenüber gestellt. Der Differenzbetrag der Bruttokosten gilt dann als "Schaden".

Die betroffene KV Schleswig-Holstein rät ihren Vertragsärzten deshalb, Impfrezepte für Influenza-Impfstoffe für die Saison 2012/13 über die Apotheke nur noch zeitnah zum Beginn der Impfsaison und sukzessive fraktioniert in überschaubaren Mengen entsprechend der Nachfrage durch die Patienten anzufordern. Außerdem empfiehlt die KV, das Aut-idem-Kreuz nicht zu setzen, um die Rabattverträge der AOK NordWest zur Geltung zu bringen. Auch rät die KV dringend davon ab, schon Monate vor der Impfsaison bei Pharmafirmen Kontingente vorzubestellen.

In Sachsen-Anhalt hat man bereits auf solche Regressforderungen der Kassen reagiert und die Belieferung mit Grippeimpfstoff zentralisiert. Nach Angabe der Kassenärztlichen Vereinigung läuft das aber nicht problemlos ab. Es gab landesweit mehr als 100 Probleme bei der Belieferung der Ärzte mit dem Impfstoff. Unter anderem sei die Kühlkette mehrfach unterbrochen worden und eine Reihe von Ärzten hätten durch das zentrale Verfahren Impfstoffe nicht ständig vorrätig, da ihre Lagerkapazitäten begrenzt sind. Die Folge: Bereits 2010 lag die Impfrate in Sachsen-Anhalt $14 \%$ unter den langjährigen Mittel- werten. 2011 wird sich dieser volkswirtschaftlich bedeutungsvolle Vorgang vermutlich noch verschlimmern.

\section{MMW Kommentar}

In bemerkenswerter Weise hat die KV Hessen das Problem gelöst. Dort werden die Ärzte auf Apotheken hingewiesen, die nicht verbrauchte Impfstoffe ohne Belastung des Verordnungsbudgets wieder zurücknehmen. Als Ausgleich für den Aufwand, den die Praxen durch dieses Impfmanagement haben, erhalten sie zusätzlich zum Impfhonorar eine Managementpauschale. So wie es aussieht, klappt das Modell auch, das auf drei Jahre ausgerichtet ist. Eine Impfstoff-Verlustquote von 9,419 Mio € im Jahr 2008 konnte praktisch halbiert werden. Die Einsparung von 4,985 Mio. € wird nun geteilt, und die KV Hessen kann aus ihrem Anteil eine Pauschale von 1,50 Euro pro Impfung finanzieren.

\section{Bei Privatliquidation auf Verjährung achten}

- Ärztliche Honorarforderungen unterliegen gemäß § 195 Bürgerliches Gesetzbuch (BGB) einer dreijährigen Verjährungsfrist. Die Verjährung beginnt mit dem Schluss des Jahres, in dem der Anspruch entstanden bzw. die Rechnung erstellt ist.

Nach § 12 GOÄ wird der Honoraranspruch des Arztes gegenüber dem Privatpatienten erst fällig, wenn der Arzt eine den Vorschriften der GOÄ entsprechende Rechnung erteilt hat. Hierzu gehört insbesondere das Datum der Erbringung der Leistung, die Bezeichnung der einzelnen berechneten Leistungen, deren Zuordnung zu einer bestimmten Gebührennummer, sowie der jeweilige Betrag und der Steigerungssatz. Damit keine Verjährung des Honoraranspruches eintritt, sollte deshalb zeitnah liquidiert werden.

Im § 286 BGB ist geregelt, dass der Patient spätestens dann in Verzug gerät, wenn er nicht innerhalb von 30 Tagen nach Fälligkeit und Zugang der Rechnung zahlt. Auf diese

\section{MMW Kommentar}

Honorarforderungen aus Rechnungsstellungen im Jahr 2008 verjähren folgerichtig mit Ablauf des 31.12.2011. Den Eintritt der Verjährung kann man verhindern. Hierfür reicht es aber nicht, dem Patienten eine oder mehrere Mahnungen zu übersenden. Eine Unterbrechung der Verjährung tritt nur dann ein, wenn der Honoraranspruch durch Mahnbescheid oder Klage geltend gemacht wird. Im Falle der Klage oder des Mahnbescheides muss eine Zustellung vor Ablauf der Verjährungsfrist erfolgen. spezielle Regelung muss der Patient in der Rechnung gesondert hingewiesen werden. Ab dem Zeitpunkt des Verzugseintritts entsteht zusätzlich ein Anspruch auf Zinsen.
Der Mahnbescheid oder die Klage muss vor dem 31.12. bei Gericht eingegangen sein. Eine Unterbrechung der Verjährung tritt aber nur ein, wenn der Mahnbescheid oder die Klage dem Patienten im Sinne des $§ 167$ Zivilprozessordnung (ZPO) i. V. m. § $203 f f$. $B G B$ zugestellt wird. Honorarrechnungen aus dem Jahre 2008 sollten spätestens im Laufe der Monate November und Dezember 2011 einem Anwalt bzw. der ärztlichen Verrechnungsstelle zur gerichtlichen Geltendmachung übergeben werden. 